\title{
Change management with empowerment of nursing staff to reduce urinary catheter use
}

\author{
N Bartlomé ${ }^{*}$, A Conen ${ }^{1}$, E Bucheli', S Schirlo², CA Fux ${ }^{1}$ \\ From 3rd International Conference on Prevention and Infection Control (ICPIC 2015) \\ Geneva, Switzerland. 16-19 June 2015
}

\section{Introduction}

Catheter-associated urinary tract infections (CAUTI) are the most common nosocomial infections.

\section{Objectives}

We used a multi-modal interdisciplinary intervention to reduce CAUTI with three key elements: stringent indications for UC insertion, shifting the task to decide on urinary catheter (UC) removal from physicians to nurses and an automatic electronic alert for catheter removal as key elements.

\section{Methods}

Non-randomized intervention study.

\section{Patients and methods}

We included all patients with a newly inserted UC at any time during hospitalization. The 13-months study comprised a baseline and 2 intervention phases. Clinical endpoints included the number of catheter days per 1'000 hospital days, the duration of catheterization as well as the rates of inserted catheters and CAUTI. Process endpoints compared changes in attitudes and knowledge about UC and CAUTI between physicians and nurses.

\section{Results}

Overall, 9'306 patients were screened for newly inserted UC, of them 513 (5.5\%) were included. In these 513 patients, the number of catheter days was reduced from 88.5 to 31.9 days per 1'000 hospital days $(\mathrm{p}<0.001)$ with a mean and median reduction of the duration of catheterization from 7.2 to 3.8 and 5 to 3 days, respectively $(\mathrm{p}<0.001)$. The number of overall CAUTI was reduced with a risk ratio of 0.31 (95\% CI 0.19-0.49) per 1'000 hospital days and of 0.35 (95\% CI 0.21-0.57) per 1'000 hospital admissions. Significant changes in task-shifting from physicians to nurses and in indications for UC were documented.

\section{Conclusion}

Behavioral changes including the empowerment of nurses resulted in significant reductions in the rate and duration of urinary catheterization as well as CAUTI.

\section{Disclosure of interest}

None declared.

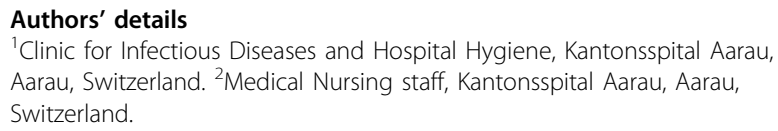

Published: 16 June 2015

\section{References}

1. Klevans RM, Edwards JR, Richard CL, et al: Estimating health careassociated infections and deaths in US hospital. Pub Health Report 2007, 122:160-166.

2. Kilgore ML, Ghosh K, Beavers CM, et al: The costs of nosocomial infections. Med Care 2008, 46:101-4.

3. Graves N, Tong E, Mortin AP, et al: Factors associated with health careacquired urinary tract infection. Am J Infect Control 2007, 35(6):387-392.

4. Egger M, Balmer F, et al: Reduction of urinary catheter use and prescription of antibiotics for asymptomatic bacteriuria in hospitalised patients in internal medicine. Swiss Med Wkly 2013, 143:w 13796.

doi:10.1186/2047-2994-4-S1-P217

Cite this article as: Bartlomé et al:: Change management with empowerment of nursing staff to reduce urinary catheter use. Antimicrobial Resistance and Infection Control 2015 4(Suppl 1):P217. 